\title{
EDITORIAL
}

\section{DYSPHAGIA, DEMENTIA AND FRAILTY}

\author{
M. PAYNE ${ }^{1}$, J.E. MORLEY ${ }^{2}$
}

1. Department of Otolaryngology, Saint Louis University, St. Louis, Missouri, USA; 2. Division of Geriatric Medicine, Saint Louis University School of Medicine, St. Louis, Missouri. Corresponding author: John E. Morley, MB, BCh, Division of Geriatric Medicine, 1402 S. Grand Blvd., M238, St. Louis, MO, USA 63104, Email: john.morley@ health.slu.edu

Dysphagia occurs in 15 to $23 \%$ of older persons living in the community (1-4). It is prevalent in hospitalized patients, reaching nearly $50 \%$ and up to $90 \%$ of hospitalized patients with Community Acquired Pneumonia (4, 5). A study from 19 countries found that dysphagia was present in $13.4 \%$ of nursing home residents (6). Patients with dementia and dysphagia are more likely to aspirate than nondemented patients (7). Patients with dementia and dysphagia have twice the chance of dying with aspiration pneumonia than those without aspiration (8). As patients with dementia experience decline in their cognitive and functional abilities, behavioral eating deficits become more common and impair their feeding and swallowing abilities. In persons with end stage dementia only $24 \%$ feed themselves and $18 \%$ are fed (9). The rest either refuse feeding $(26 \%)$ or choke on their food $(32 \%)$. This is not surprising as persons with Alzheimer's disease have deficits in all 5 senses, which are essential for the process of eating. Among the eating and drinking problems seen in dementia are: Food refusal, distractibility, visual agnosia, swallowing and feeding apraxia, pocketing food, spitting food, excessive swallows, rapid eating, absent chewing, and delayed or impaired pharyngeal swallow.

Dysphagia can occur early in the dementia process (10) with swallowing problems becoming more pronounced as the disease progresses. Dysphagia is often not recognized in persons with dementia. The signs and symptoms of dysphagia in a patient with dementia are outlined in Table I. Dysphagia can predispose these patients in many serious health consequences such as weight loss, dehydration, malnutrition, and aspiration pneumonia $(11,12)$.

Eating and swallowing requires cognitive awareness, visual recognition of food, physiologic response, motor planning and execution and patterned sensorimotor responses (13). Thus, as patients experience deficits in attention, initiation, orientation, recognition, executive function, decision-making and apraxia, the process of eating and swallowing is affected. Changes to swallowing physiology vary by the type and severity of dementia (14). Patients with Alzheimer's present with increased oral transit duration, which may be related to sensory awareness of the bolus $(15,16)$. Persons with Alzheimer's dementia tend to have an increased number of swallows for any given amount in their mouth, a longer duration of the swallow and a longer period of apnea (17). As the disease progresses, these patients develop reduced pharyngeal clearance, reduced upper esophageal opening, and penetration and/or aspiration (18). Patients with dementia also have a decreased sympathetic skin response during swallowing (19). Persons with Lewybody dementia (20) tend to be more likely to have swallowing dysfunction (90\%) compared to Alzheimer's disease (21). They have high levels of pharyngeal dysfunction and aspirate around $45 \%$ of the time. In persons with frontotemporal dementia about $60 \%$ have dysphagia, but this is only recognized by the caregiver in a third of patients (22). These patients tend to eat rapidly and compulsively and take large bolus sizes (22). There is more frequent early leakage into the pharynx and incomplete pharyngeal clearance. Persons given atypical antipsychotics for behavioral disturbances have markedly increased pneumonia associated with an increased risk of having dysphagia (23-25).

Swallowing evaluation in the individual with dementia begins at the bedside, with a clinical swallow evaluation. This allows the speech pathologist to assess for signs and symptoms of dysphagia but also evaluate functional aspects of swallowing, such as feeding and eating behaviors. A clinical swallow evaluation is not adequate to rule out aspiration, as it underestimates the aspiration risk in individuals who aspirate (14). Thus, an instrumental evaluation of swallowing is recommended to identify the impairment and determine further management of dysphagia.

Dysphagia management may include compensatory and behavioral strategies, diet and environmental modifications. Compensatory and postural changes can be used to alter the swallow in order to compensate for deficits found in an instrumental evaluation of swallowing. Compensatory strategies may include swallow maneuvers or modifications to eating behaviors. Swallow maneuvers can be utilized to modify different physiologic swallowing deficits, such as utilizing a supraglottic swallow maneuver which employs a voluntary breath hold to facilitate early laryngeal closure and protect the airway during the swallow (26). Postural changes, such as a chin tuck or a head tilt, are used to alter the speed and flow direction of a food or liquid, with the intent of protecting the airway to improve safety of the swallow (27). Unfortunately, compensatory and postural changes may not be appropriate for patients with dementia because they require the patient to utilize these strategies with each swallow.

Diet modifications to food textures and liquid viscosity are commonly utilized in management of dysphagia in individuals with dysphagia. Wang et al (28) found that thickened liquids had no statistical decreases in pneumonia and this was true for both nectar-thickened and honey-thickened groups. However, the thickened liquid groups were more likely to be dehydrated, 


\section{THE JOURNAL OF NUTRITION, HEALTH \& AGING@}

have a fever and develop a urinary tract infection. Recent innovations have shown that modified food such as foams, molds, finger food, soaking foods or thickened ice cream can greatly enhance the meal with little increase in aspiration. Changing taste, temperature, volume or viscosity of food may also be used to increase sensory awareness (13).

Interventions to modify the environments such as reducing distractions, limiting background noise, and creating mealtime routines are also commonly utilized to promote successful eating (27). Specialized feeding techniques such as the Spaced Retrieval Technique (29) or Backward Chaining (30) may enhance the ability of patients with dementia to self-feed and enjoy their meal. Hand feeding may become necessary with progression of the disease, should other techniques no longer provide benefit. However, dependency for feeding elevates the risk of aspiration and aspiration pneumonia in patients with dysphagia (22). Furthermore, hand feeding is labor intensive and takes between 45 to 90 minutes a day to feed patients with dementia (31). Most staff spend less time feeding the patient than do family members or volunteers $(32,33)$. This may increase the patient's risk of aspiration. Caregivers and nursing staff are essential in promoting successful mealtimes for individuals with dementia. Training for staff in nutritional care and assistance with eating is of great importance in maintaining nutritional status.

It is important to establish the person and their family's attitude towards a feeding tube early when they have dysphagia. Too often decisions are made for the first time during a crisis situation when the person has been admitted to hospital. Twothirds of feeding tubes are placed during an acute hospital stay (34). Although a feeding tube is thought to reduce the risk of aspiration pneumonia, this has not proven to be true (35). Furthermore, there appears to be little difference in survival between persons who are fed by hand and then fed through a gastrostomy tube (36-38). A Cochrane systematic review found that there is "Insufficient evidence to suggest that enteral tube feeding is beneficial in persons with advanced dementia" (39) though there may be limited adverse effects of the intervention (40). McCann et al (41) found that food and fluid administration beyond that requested by the patient does not appear to improve the comfort of terminally ill patients.

Dysphagia is a common cause of protein energy undernutrition in the persons with dementia. Persons with dementia should be regularly screened for anorexia with tools such as the Simplified Nutrition Appetite Questionnaire (SNAQ) $(42,43)$ and for poor nutrition with the MiniNutrition Assessment (MNA) or its short form (44-46). The dietitian or speech therapist should observe the person eating and the interprofessional team should develop innovative strategies to prevent dysphagia and weight loss early in the disease.

\section{The Frailty Phenotype and Dysphagia}

Frailty is the condition when the person is stressed she has diminished ability to carry out important practiced activities of daily living (47). It should be distinguished from disability. Fried et al (48) developed a physical phenotype of frailty consisting of weight loss, exhaustion, weakness (low grip strength), slow walking speed and low physical activity. This physical phenotype is highly predictive of falls, declining mobility and activities of daily living, hospitalizations and death (49). The FRAIL is a rapid screen for frailty that has been validated as a predictor of poor outcomes in over 25 studies $(50,51)$. It consists of fatigue, resistance (climb a flight of stairs), aerobic (walk one block), illnesses (more than 5 ) and loss of weight (5\% in 6 months) (52). Guidelines for the management of frailty have been published (53). They recommend identification of frailty with a validated tool and, in persons who are frail, a progressive resistance exercise program and management of polypharmacy.

Frailty is associated with an increased prevalence of dysphagia (54-57). The major components of frailty leading to increased dysphagia are sarcopenia, functional impairment, and drugs affecting swallowing (58). Frailty is often associated with increased inflammation (59).

Sarcopenia is defined as a loss of muscle mass that leads to a loss of function $(60,61)$. Grip strength and walking speed are associated with tongue pressure and to a lesser extent jaw opening force in men (62-68). Similarly, head lifting strength is associated with dysphagia and malnutrition in older persons (69). Importantly, lingual exercises and head extension swallowing exercises improved swallowing in older adults (7073). For these reasons, it is reasonable that the EAT-10 should be carried out in all frail and sarcopenic patients to assist in identification of individuals with dysphagia (74).

The interrelationship between oropharyngeal dysphagia, sarcopenia and frailty is shown in Figure 1. The approach to the management of oropharyngeal dysphagia requires the utilization of Patient Centered (P4) Medicine with an interprofessional team $(75,76)$. While the $\mathrm{P} 1$ - Predictive component of dysphagia is still in its infancy, there is some evidence that neurostimulation may work better in association with some markers such as brain derived neurotrophic factor (77) and there is the possibility that high circulating myostatin levels may be ideal for treatment with myostatin peptobodies $(78,79)$ at the P-2 level (Preventive) screening with the EAT10 in all FRAIL and SARC-F positive patients makes sense. At the P-3 (Personalized) level there are a variety of early therapies that can be custom fitted to the patient's need. Finally, at the P-4 level (Participation) patient with dysphagia need ongoing support to assure compliance. 


\section{DYSPHAGIA, DEMENTIA AND FRAILTY}

\section{Table 1}

Symptoms of Dysphagia in a Patient with Dementia

\begin{tabular}{ll}
\hline 1. & Weight loss \\
2. & Refusal to eat \\
3. & Refuses to open mouth \\
4. & Leaves food on plate \\
5. & Spits out food \\
6. & Coughs while eating \\
7. & Does not swallow \\
8. & Touches throat or chest while swallowing \\
9. & Drooling \\
10. & A wet or "gurgly" voice \\
11. & Chews without swallowing \\
12. & Recurrent urinary tract infections due to dehydration \\
\hline
\end{tabular}

Figure 1

Mechanisms of Dysphagia

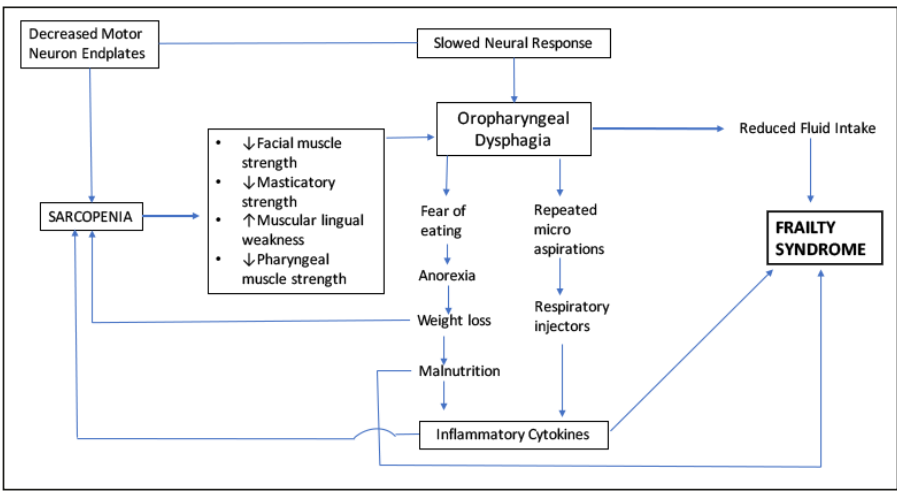

\section{References}

1. Madhavan A, LaGorio LA, Crary MA, Dahl WJ, Carnaby GD. Prevalence of and risk factors for dysphagia in the community dwelling elderly: A systematic review. J Nutr Health Aging 2016;20:806-815.

2. Ortega $\mathrm{O}$, Martin A, Clave P. Diagnosis and management of oropharyngeal dysphagia among older persons, state of the art. J Am Med Dir Assoc 2017;18:576-582.

3. Payne MA, Morley JE. Dysphagia: A new geriatric syndrome. J Am Med Dir Assoc 2017;18:555-557.

4. Morley JE. Dysphagia and aspiration. J Am Med Dir Assoc 2015;16:631-634.

5. Ortega O, Martin A, Clave P. Diagnosis and management of oropharyngeal dysphagia among older persons, state of the art. J Am Med Dir Assoc 2017;18:576-582.

6. Streicher M, Wirth R, Schindler K, Sieber CC, Hiesmayr M, Volkert D. Dysphagia in nursing homes-results from the NutritionDay project. J Am Med Dir Assoc 2017; Oct 10. Doi: 10.1016/j.jamda.2017.08.015.

7. Rosler A, Pfeil S, Lessmann H, Hoder J, Befahr A, von Reinteln-Kruse W. Dysphagia in dementia: Influence of dementia severity and food texture on the prevalence of aspiration and latency to swallow in hospitalized geriatric patients. J Am Med Dir Assoc 2015;16:697-701

8. Manabe T, Mizukami K, Akatsu H, Hasizume Y, Ohkubo T, Kudo K, Hazawa N. Factors associated with pneumonia-caused death in older adults with autopsyconfirmed dementia. Intern Med 2017;56:907-914.

9. Volicer L, Seltzer B, Rheaume Y, Karner J, Glennon M, Riley ME, Crino P. Eating difficulties in patients with probably dementia of the Alzheimer type. J Geriatr Psychaitry Neurol 1989;2:188-195.

10. Wirth R, Dziewas R, Beck AM, Clave P, Hamdy S, Heppner HJ, Langmore $\mathrm{S}$, Leischker AH, et al. Oropharyngeal dysphagia in older persons - from pathyphysiology to adequate intervention: A review and summary of an international expert meeting. Clin Interv Aging 2016;11:189-208.
11. Clavé P, Rofes L, Carrión S, Ortega O, Cabré M, Serra-Prat M, et al Pathophysiology, relevance and natural history of oropharyngeal dysphagia among older people. Nestle Nutr Inst Workshop Ser. 2012;72:57-66.

12. Easterling CS, Robbins E. Dementia and dysphagia. Geriatr Nur. 2008;29(4):275-85.

13. Rogus-Pulia N, Malandraki GA, Johnson S, Robbins J. Understanding dysphagia in dementia: the present and the future. Curr Phys Med Rehabil Rep. 2015;3:86-97

14. Alagiakrishnan K, Bhanji RA, Kurian M. Evaluation and management of oropharyngeal dysphagia in different types of dementia: a systematic review. Arch Gerontol Geriatr. 2013;56:1-9.

15. Humbert IA, McLaren DG, Kosmatka K, Fitzgerald M, Johnson S, Porcaro E, et al Early deficits in cortical control of swallowing in Alzheimer's disease. J Alzheimers Dis JAD. 2010; 19(4):1185-97.

16. Priefer BA, Robbins J. Eating changes in mild-stage Alzheimer's disease: a pilot study. Dysphagia. 1997;12(4):212-21.

17. Seçil Y, Arici S, Incesu TK, Gurgor N, Beckmann Y, Artekin C. Dysphagia in Alzheimer's disease. Neurophysiol Clin 2016;46:171-178.

18. Horner J, Alberts MJ, Dawson DV, Cook GM. Swallowing in Alzheimer's disease. Alzheimer Dis Assoc Disord. 1994;8(3): 177-89.

19. Arici S, Gurgor N, Secil Y, Incesu TK, Ozdemirkiran T, Ce P, Celebisoy M, et al. Sympathetic skin responses in adult humans during sequential swallowing. Neurophysiol Clin 2013;43:11-17.

20. Morley JE. Dementia with Lewy bodies: A common condition in nursing homes? J Am Med Dir Assoc 2013;14:713-714.

21. Londos E, Hanxsson O, Alm Hirsch I, Janneskog A, Bulow M, Palmqvist S. Dysphagia in Lewy body dementia - a clinical observational study of swallowing function by videofluoroscopic examination. BMC Neurol 2013;13:140. Doi: 10.1186/1471-2377-13-140.

22. Langmore SE, Olney RK, Lomen-Hoerth C, Miller BL. Dysphagia in patients with frontotemporal lobar dementia. Arch Neurol 2007;64:58-62.

23. Herzig SJ, LaSalvia MT, Naidus E, Rothbert MB, Zhou W, Gurwitz JH, Marcantonio ER. Antipsychotics and the risk of aspiration pneumonia in individuals hospitalized for nonpsychiatric conditions: A cohort study. J Am Geriatr Soc 2017;Nov 2 doi: 10.111/jgs.15066 [Epub ahead of print]

24. Tolppanen AM, Koponen M, Tanskanen A, Lavikainen P, Sund R, Tlihonen J, et al. Antipsychotic use and risk of hospitalization or death due to pneumonia in persons with and those without Alzheimer disease. Chest 2016;150:1233-1241.

25. Mehta S, Pulungan Z, Jones BT, Teigland C. Comparative safety of atypical antipsychotics and the risk of pneumonia in the elderly. Pharmacoepidemiol Drug Saf. 2015;24:1271-1280.

26. Sura L, Madhavan A, Carnaby G, Crary MA. Dysphagia in the elderly: management and nutritional considerations. Clin Interv Aging. 2012;7:287-98.

27. Aselage, MB, Amella EJ, Watson, R. State of the science: alleviating mealtime difficulties in nursing home residents with dementia. Nurs Outlook. 2011;59:210-214.

28. Wang $\mathrm{CH}$, Charlton B, Kohlwes J. The horrible taste of nectar and honeyinappropriate use of thickened liquids in dementia: A teachable moment. JAMA Intern Med 2016;176:735-736.

29. Benigas JE, Bourgeois M. Using spaced retrieval with external aids to improve use of compensatory strategies during eating for persons with dementia. Am J Speech Lang Pathol 2016;25:321-334.

30. Caffò AO, Hoogeveen F, Groenendaal M, Perilli AV, Picucci L, Lancioni GE, Bosco A. Intervention strategies for spatial orientation disorders in dementia: A selective review. Dev Neurorehabil 2014;17:200-209.

31. Simmons SF, Schnelle JF. Feeding assistance needs of long-stay nursing home residents and staff time to provide care. J Am Geriatr Soc 2006;54:919-924.

32. Kayser-Jones J. Mealtime in nursing homes: The importance of individualized care. J Gerontol Nurs 1996;22:26-31

33. Simmons SF, Keeler E, Zhuo X, Hickey KA, Sato HW, Schnelle JF. Prevention of unintentional weight loss in nursing home residents: A controlled trial of feeding assistance. J Am Geriatr Soc 2008;56:1466-1473.

34. Teno JM, Mitchell SL, Gozalo PL, Dosa D, Hsu A, Intrator O, Mor V. Hospital characteristics associated with feeding tube placement in nursing home residents with advanced cognitive impairment. JAMA 2010;303:544-550.

35. Marik PE. Aspiration pneumonitis and aspiration pneumonia. N Engl J Med 2001;344(9):665-71.

36. Mitchell SL, Mor V, Gozalo PL, Servadio JL, Teno JM. Tube feeding in US nursing home residents with advanced dementia, 2000-2014.

37. Mitchell SL, Buchanan JL, Littlehale S, Hamel MB. Tube-feeding versus handfeeding nursing home residents with advanced dementia: A cost comparison. J Am Med Dir Assoc 2003;4:27-33.

38. Kuo S, Rhodes RL, Mitchell SL, Mor V, Teno JM. Natural history of feeding-tube in nursing home residents with advanced dementia. J Am Med Dir Assoc 2009;10:264270 .

39. Sampson EL, Candy B, Jones L. Enteral tube feeding for older people with advanced dementia. Cochrane Database Syst Rev 2009;15:CD007209. doi:10.1002/14651858

40. Ribeiro Salomon AL, Varvalho Garbi Novaes MR. Outcomes of enteral nutrition for patients with advanced dementia: A systematic review. J Nutr Health Aging 2015;19:169-177.

41. McCann RM, Hall WJ, Groth-Juncker A. Comfort care for terminally ill patients. The 


\section{THE JOURNAL OF NUTRITION, HEALTH \& AGING@}

appropriate use of nutrition and hydration. JAMA 1994;272:1263-1266.

42. Pilgrim AL, Baylis D, Jameson KA, Cooper C, Sayer AA, Robinson SM, Roberts HC. Measuring appetite with the Simplified Nutritional Appetite Questionnaire identifies hospitalised older people at risk of worse health outcomes. J Nutr Health Aging 2016;20:3-7.

43. Wilson MM, Thomas DR, Rubenstein LZ, Chibnall JT, Anderson S, Baxi A, Diebold MR, Morley JE. Appetite assessment: Simple appetite questionnaire predicts weight loss in community-dwelling adults and nursing home residents. Am J Clin Nut 2005;82:1074-1081.

44. Skinnars Josefsson M, Nydahl M, Persson I, Mattsson Sydner Y. Quality indicators of nutrition care practice in elderly care. J Nutr Health Aging 2017;21:1057-1064.

45. Schrader E, Grosch E, Bertsch T, Sieber CC, Volkert D. Nutritional and functional status in geriatric day hospital patients - MNA short form versus full MNA. J Nutr Health Aging 2016;20:918-926.

46. Lera L, Sanchez H, Angel B, Albala C. Mini nutritional assessment short-form: Validation in five Latin American cities. SABE study. J Nutr Health Aging 2016;20:797-805

47. Morley JE, Vellas B, van Kan GA, Anker SD, Bauer JM, Bernabei R, et al. Frailty consensus: A call to action. J Am Med Dir Assoc 2013;14:392-397.

48. Fried LP, Tangen CM, Walston J, Newman AB, Hirsch C, Gottdiener J, Seeman T, et al. Frailty in older adults: Evidence for a phenotype. J Gerontol A Biol Sci Med Sci 2001;56:M146-156

49. Morley JE. Frailty and sarcopenia: The new geriatric giants. Rev Invest Clin 2016;68:59-67.

50. Woo J, Leung J, Morley JE. Comparison of frailty indicators based on clinica phenotype and the multiple deficit approach in predicting mortality and physical limitation. J Am Geriatr Soc 2012;60:1478-1486.

51. Morley JE, Malmstrom TK, Miller DK. A simple frailty questionnaire (FRAIL) predicts outcomes in middle aged African Americans. J Nutr Health Aging 2012;16:601-608.

52. Abellan van Kan G, Rolland Y, Bergman H, Morley JE, Kritchevshy SB, Vellas B. The I.A.N.A. task force on frailty assessment of older people in clinical practice. J Nutr Health Agin 2008:12:29-37.

53. Dent E, Lien C, Lim WS, Wong WC, Wong Ch, Ng TP, Woo J, et al. The AsiaPacific clinical practice guidelines for the management of frailty. J Am Med Dir Assoc 2017; 18:564-575.

54. Hathaway B, Vaezi A, Egloff AM, Smith L, Wasserman-Wincko T, Johnson JT. Frailty measurements and dysphagia in the outpatient setting. Ann Otol Rhinol Laryngol 2014;123:629-635.

55. Gonzalez-Fernandez M, Humbert I, Winegrad H, Cappola AR, Fried LP. Dysphagia in old-old women: Prevalence as determined according to self-report and the 3-ounce water swallowing test. J Am Geriatr Soc 2014;62:716-620.

56. Madhavan A, LaGorio LA, Crary MA, Dahl WJ, Carnaby GD. Prevalence of and risk factors for dysphagia in the community dwelling elderly: A systematic review. J Nutr Health Aging 2016;20:806-815.

57. Nogueira D, Reis E. Swallowing disorders in nursing home residents: How can the problem be explained? Clin Interv Aging 2013;8:221-227.

58. Stoschus B, Allescher HD. Drug-induced dysphagia. Dysphagia 1993;8:154-159.

59. Velissaris D, Patzaris N, Koniari I, Koutsogiannis N, Karamouzos V, Kotroni I, Skroumpelou A, Ellul J. C-reactive protein and frailty in the elderly: A literature review. J Clin Med Res 2017;9:461-465.

60. Morley JE, von Haehling S, Anker SD, Vellas B. From sarcopenia to frailty: A road less traveled. J Cachexia Sarcopenia Muscle 2014;5:5-8.
61. McKee A, Morley JE, Matsumoto AM, Vinik A. Sarcopenia: An endocrine disorder? Endocr Pract 2017;23:1140-1149.

62. Wakasugi $\mathrm{Y}$, Tohara $\mathrm{H}$, Machida N, Nakane A, Minakuchi S. Can grip strength and/ or walking speed be simple indicators of the deterioration in tongue pressure and jaw opening force in older individuals? Gerodontology 2017;34:455-459.

63. Buehring B, Hind J, Fidler E, Krueger D, Binkley N, Robbins J. Tongue strength is associated with jumping mechanography performance and handgrip strength but not with classic functional tests in older adults. J Am Geriatr Soc 2013;61:418-422.

64. Yoshimura Y, Wakabayashi H, Bise T, Tanoue M. Prevalence of sarcopenia and its association with activities of daily living and dysphagia in convalescent rehabilitation ward inpatients. Clin Nutr 2017; Sept 23 doi: 10.1016/j.clnu.2017.09.009 [Epub ahead of print].

65. Matsuo H, Yoshimura Y. Calf circumference is associated with dysphagia in acute care inpatients. Geriatr Nurs 2017; Sep 19 doi: 10.1016/j.gerinurse.2017.08.003. [Epub ahead of print]

66. Sakai K, Nakayama E, Tohara H, Maeda T, Sugimoto M, Takehisa T, Takehisa Y, Ueda K. Tongue strength is associated with grip strength and nutritional status in older adults inpatients of a rehabilitation hospital. Dysphagia 2017:32:241-249.

67. Wakabayashi H, Maeda, Shamato H. Swallowing function, skeletal muscle mas and sarcopenia in older adults requiring long-term care. Geriatr Gerontol Int 2016;16:1175-1176.

68. Sakai K, Nakayama E, Tohara H, Kodama K, Takehisa T, Takehisa Y, Ueda K. Relationship between tongue strength, lip strength, and nutrition-related sarcopenia in older rehabilitation inpatients: A cross-sectional study. Clin Interv Aging 2017; 12:1207-1214.

69. Wakabayashi $\mathrm{H}$, Sashika $\mathrm{H}$, Matsushima $\mathrm{M}$. Head lifting strength is associated with dysphagia and malnutrition in frail older adults. Geriatr Gerontol Int 2015;15:410416.

70. Suzuki M, Maeda K, Shamoto $\mathrm{H}$, Wakabayashi $\mathrm{H}$. Effects of aging and sarcopenia on strength of swallowing muscles in older adults. Geriatr Gerontol Int 2017;17:360-361.

71. Oh JC. A pilot study of the head extension swallowing exercise: New method for strengthening swallowing-related muscle activity. Dysphagia 2016;31:680-686.

72. Yeates EM, Molfenter SM, Steele CM. Improvements in tongue strength and pressure-generation precision following a tongue-pressure training protocol in older individuals with dysphagia: Three case reports. Clin Interv Aging 2008;3:735-747.

73. Robbins J, Gangnon RE, Theis SM, Kays SA, Hewitt AL, Hind JA. The effects of lingual exercise on swallowing in older adults. J Am Geriatr Soc 2005;53:1483-1489.

74. Wakabayashi H, Matsushima M. Dysphagia assessed by the 10-item eating assessment tool is associated with nutritional status and activities of daily living in elderly individuals requiring long-term care. J Nutr Health Aging 2016;20:22-27.

75. Morley JE, Anker SD. Myopenia and precision (P4) medicine. J Cachexia Sarcopenia Muscle 2017; Sep 24 doi:10.1002/jcsm.12231 [Epub ahead of print]

76. Morley JE, Vellas B. Patient-centered (P4) medicine and the older person. J Am Med Dir Assoc 2017:18:455-459.

77. Raginis-Zborowska A, Pendleton N, Hamdy S. Genetic determinants of swallowing impairment, recovery and responsiveness to treatment. Curr Phys Med Rehabil Rep 2016;4:249-256

78. Lebrasseur NK. Building muscle, browning fat and preventing obesity by inhibiting myostatin. Diabetologia 2012;55:13-17.

79. Leger B, Derave W, de Bock K, Hespel P, Russell AP. Human sarcopenia reveals an increase in SOCS-3 and myostatin and a reduced efficiency of Akt phosphorylation. Rejuvenation Res 2008;11:163-175B. 